\title{
Ciprofloxacin, diclofenac, ibuprofen and 17a-ethinylestradiol differentially affect the activity of acetogens and methanogens in anaerobic communities
}

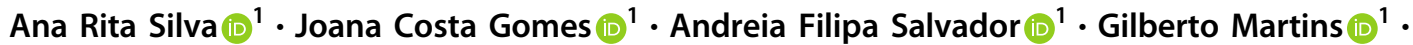 \\ Maria Madalena Alves (iD ${ }^{1} \cdot$ Luciana Pereira (D) $^{1}$
}

Accepted: 13 July 2020 / Published online: 29 July 2020

(c) Springer Science+Business Media, LLC, part of Springer Nature 2020

\begin{abstract}
Pharmaceutical compounds end up in wastewater treatment plants but little is known on their effect towards the different microbial groups in anaerobic communities. In this work, the effect of the antibiotic Ciprofloxacin (CIP), the non-steroidal anti-inflammatory drugs Diclofenac (DCF) and Ibuprofen (IBP), and the hormone $17 \alpha$-ethinylestradiol (EE2), on the activity of acetogens and methanogens in anaerobic communities, was investigated. Microbial communities were more affected by CIP, followed by EE2, DCF and IBP, but the response of the different microbial groups was dissimilar. For concentrations of 0.01 to $0.1 \mathrm{mg} / \mathrm{L}$, the specific methanogenic activity was not affected. Acetogenic bacteria were sensitive to CIP concentrations above $1 \mathrm{mg} / \mathrm{L}$, while DCF and EE2 toxicity was only detected for concentrations higher than $10 \mathrm{mg} / \mathrm{L}$, and IBP had no effect in all concentrations tested. Acetoclastic methanogens showed higher sensitivity to the presence of these micropollutants, being affect by all the tested pharmaceutical compounds although at different degrees. Hydrogenotrophic methanogens were not affected by any concentration, indicating their lower sensitivity to these compounds when compared to acetoclasts and acetogens.
\end{abstract}

\section{Graphical Abstract}

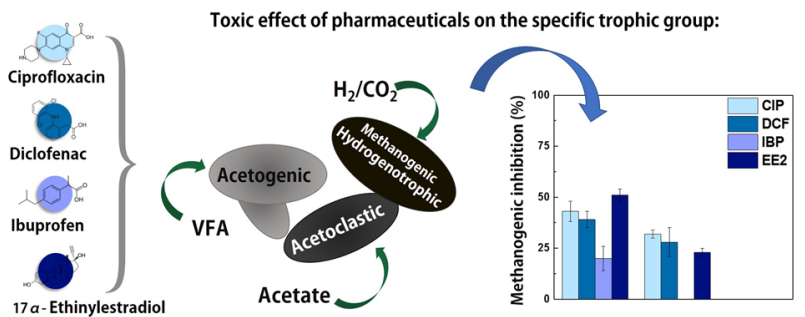

Keywords Activated sludge $\cdot$ Anaerobic digestion $\cdot$ Methanogenic activity $\cdot$ Pharmaceuticals $\cdot$ Toxicity $\cdot$ Wastewater

These authors contributed equally: Silva Ana Rita and Costa Joana Gomes

Supplementary information The online version of this article (https:// doi.org/10.1007/s10646-020-02256-7) contains supplementary material, which is available to authorized users.

Luciana Pereira

lucianapereira@deb.uminho.pt

1 Centre of Biological Engineering, University of Minho, 4710-057 Braga, Portugal

\section{Introduction}

The contamination of wastewater with pharmaceuticals is an environmental problem and a public health concern (Carpenter et al. 2002; Vasquez et al. 2014). Some pharmaceuticals cause endocrine disruption (Khetan and Collins 2007; Corcoran et al. 2010) and increase bacterial resistance to antibiotics (Bouki et al. 2013), leading to important shifts in microbial communities in the ecosystem (Fountoulakis et al. 2008; Ji et al. 2013). Although 
pharmaceuticals are usually detected in wastewater in relatively low concentrations (in the range of $\mathrm{ng} / \mathrm{L}$ to $\mu \mathrm{g} / \mathrm{L}$ ) (Jones et al. 2005; Quintana et al. 2005; Liebig et al. 2006; Radjenovic et al. 2007; Scheurell et al. 2009; Jelic et al. 2011; Gonzalez-Gil et al. 2016; Subedi and Loganathan 2016), higher levels (14 to $31 \mathrm{mg} / \mathrm{L}$ of ciprofloxacin (CIP)) have already been detected in the effluents of wastewater treatment plants (WWTP) in India (Larsson et al. 2007; Fick et al. 2009) as well as in the surface water from two lakes in India that were not contaminated by the WWTP, and in wells of six nearby villages (Fick et al. 2009). In Portugal, $17.5 \mu \mathrm{g} / \mathrm{L}$ of CIP (Pereira et al. 2015), $2.4 \mu \mathrm{g} / \mathrm{L}$ of ibuprofen (IBP) (Pereira et al. 2015; Sousa 2015), $8.6 \mu \mathrm{g} / \mathrm{L}$ of diclofenac (DCF) (Pereira et al. 2015; Sousa 2015) and $0.19 \mu \mathrm{g} / \mathrm{L}$ of $17 \alpha$-ethinylestradiol (EE2) (Fonseca et al. 2013), are usually found in wastewater (WWTP influents). However, the concentration of pharmaceutical compounds adsorbed in sewage sludge can be much higher. For example, sewage sludge from different sites in USA (US EPA 2009) contained CIP and IBP concentrations in the range of 74.5 to $47500 \mu \mathrm{g} / \mathrm{Kg}$ of dry-weight sludge, and 99.5 to $11900 \mu \mathrm{g} / \mathrm{Kg}$ of dry-weight sludge, respectively. In a Spanish WWTP, DCF reached concentrations of $200 \mu \mathrm{g} / \mathrm{Kg}$ of dry-weight of primary sludge (Radjenović et al. 2009), and in Germany, DCF concentrations of $7020 \mu \mathrm{g} / \mathrm{Kg}$ total suspended solids in primary sludge and $310 \mu \mathrm{g} / \mathrm{Kg}$ of total suspended solids in secondary sludge could be detected (Ternes et al. 2004).

Dissemination of pharmaceuticals in the environment via contaminated sludge and effluents has been found in soil (Carter et al. 2014; Li 2014; Malmborg and Magnér 2015), crops (Wu et al. 2012), surface water (Zhou et al. 2009; Mei et al. 2018), groundwater and even drinking water (Carvalho et al. 2013; Cetecioglu et al. 2013). To date, several sludge and wastewater technologies have been proposed to solve this problem, and include conventional activated sludge and membrane bioreactor treatments, sedimentation, hydrolysis and chlorination (Carvalho et al. 2013; Cetecioglu et al. 2013; Jung et al. 2015; Krzeminski et al. 2019). However, treatment efficiencies are still very low and/or involve high costs, require high energy input, and may produce residual toxic by-products (Trapido et al. 2014; Jung et al. 2015; Silva et al. 2016; Hasan et al. 2016; Campbell 2017). Therefore, more research is needed to develop new treatment solutions for sludge and wastewater contaminated with pharmaceuticals. The treatment by anaerobic digestion (AD) is a possibility which brings several advantages such as the recovery of energy from sludge and wastewater (in the form of biogas), thus contributing to the energy autonomy of WWTP (Eiroa et al. 2012; Mayumi et al. 2016; Chen et al. 2017). However, prior application of $\mathrm{AD}$ to contaminated waste/wastewater it is important to evaluate the possible effects of pharmaceuticals on the activity of anaerobic microorganisms. In $\mathrm{AD}$, microbial communities are composed by several microbial groups with distinct physiological activities and substrate specificities, that interact with each other. For instance, the last steps of AD are catalyzed by acetogenic bacteria, which convert volatile fatty acids (e.g., butyrate, propionate) to acetate, hydrogen and carbon dioxide, and by acetoclastic and hydrogenotrophic methanogens that utilize the acetate and the hydrogen (plus carbon dioxide) for methane production, respectively. Acetogenesis and methanogenesis are crucial steps in AD, occurring after hydrolysis and acidogenesis of complex organic matter (i.e., proteins, carbohydrates or lipids). Thus, it is desirable that the activity of acetogens and methanogens is not compromised by the presence of toxicants in $\mathrm{AD}$, to guarantee the treatment efficiency.

The literature reports a number of studies where complex substrates such as casein, glucose or peptone were used to assess the effect of pharmaceuticals, instead of the direct substrates for methanogens and acetogens (Fountoulakis et al. 2004; Campbell 2013; Liu et al. 2013; Zhao et al. 2018).

In this work, the effect of CIP, IBP, DCF and EE2, on the activity of anaerobic communities, was investigated by using specific substrates for methanogens $\left(\mathrm{H}_{2} / \mathrm{CO}_{2}\right.$ for hydrogenotrophic methanogens, and acetate for acetoclastic methanogens) and acetogens (a mixture of volatile fatty acids), and by following methane production.

\section{Materials and methods}

\section{Preparation of pharmaceutical solutions}

CIP (CAS 85721-33-1, purity $\geq 98 \%$ ), IBP (CAS 15687$27-1$, purity $\geq 98 \%$ ), DCF (CAS $15307-79-6$, purity $\geq 98 \%$ ) and EE2 (CAS 57-63-6, purity $\geq 98 \%$ ) were purchased from Sigma-Aldrich. The tested concentrations of each pharmaceutical ranged between $0.01 \mathrm{mg} / \mathrm{L}$ and $100 \mathrm{mg} / \mathrm{L}$. For the concentrations between $0.01 \mathrm{mg} / \mathrm{L}$ and $0.1 \mathrm{mg} / \mathrm{L}$, stock solutions of $1 \mathrm{mg} / \mathrm{L}$ were prepared in deionized water. For higher concentrations, a stock of $1250 \mathrm{mg} / \mathrm{L}$ was prepared also in deionized water for DCF, while for the other pharmaceuticals, due to their low solubility in water, it was necessary to prepare stock solutions (1250 mg/L) as following: (1) solution of CIP in water with a few drops of hydrochloric acid (2 M); (2) addition of methanol to IBP and (3) addition of ethanol to EE2, as described in Table 1. CIP has a water solubility of $30 \mathrm{~g} / \mathrm{L}$ at $20^{\circ} \mathrm{C}$, which is enhanced when it is in the ionic form, explaining the higher solubility in acidic media. IBP and $\mathrm{EE} 2$, also have low solubility in water, $21 \mathrm{mg} / \mathrm{L}$ at $25^{\circ} \mathrm{C}$ and $11.3 \mathrm{mg} / \mathrm{L}$ at $27^{\circ} \mathrm{C}$. 
Table 1 Experimental conditions for the determination of the toxicity effect of pharmaceuticals towards acetogenic and methanogenic communities

\begin{tabular}{llll}
\hline Pharmaceutical & Pharmaceutical $(\mathrm{mg} / \mathrm{L})$ & Solvent & Controls \\
\hline CIP & $0.01 ; 0.1$ & Water & B; SC \\
& $1 ; 5 ; 10 ; 50$ and 100 & Water with $\mathrm{HCl}^{\mathrm{a}}$ & \\
DCF & $0.01 ; 0.1 ; 1 ; 5 ; 10 ; 50$ and 100 & Water & B; SC \\
IBP & $0.01 ; 0.1$ & Water & B; SC \\
& $1 ; 5 ; 10 ; 50$ & Methanol/Water 37\% (v/v) & B; SC; OSS and OS \\
EE2 & $0.01 ; 0.1$ & Water & B; SC \\
& $1 ; 5 ; 10 ; 50$ & Ethanol/Water $47 \%(\mathrm{v} / \mathrm{v})$ & B; SC; OSS and OS
\end{tabular}

${ }^{a} 250 \mu \mathrm{L}$ of $\mathrm{HCl}(2 \mathrm{M})$ were added to $100 \mathrm{~mL}$ of the stock solution prepared in deionized water

Blank (B) - Without substrate, pharmaceutical or solvent; Substrate control (SC) - Only substrate added to the buffer (no pharmaceutical and no solvent); Organic solvent controls - No pharmaceutical addition to the buffer, only the organic solvent in the concentrations correspondent to that of the tests with pharmaceuticals, either with substrate (OSS) or without substrate (OS)

\section{Batch experiments set-up}

The effect of pharmaceuticals on $\mathrm{AD}$ was assessed by determining the specific methanogenic activity (SMA) of an anaerobic granular sludge, collected from the anaerobic digester treating a brewery wastewater. The assays were carried out in the presence of increasing concentrations of CIP, IBP, DCF and EE2 (Table 1). SMA of the anaerobic sludge was determined as described elsewhere (Alves et al. 2001).

The effect of CIP, IBP, DCF and EE2 on the activity of hydrogenotrophic methanogens, acetoclastic methanogens and acetogens was determined by incubating the anaerobic sludge with the following substrates as carbon and energy sources: $\mathrm{H}_{2} / \mathrm{CO}_{2}\left(80: 20 \% \mathrm{v} / \mathrm{v}\right.$, at $\left.1.7 \times 10^{5} \mathrm{~Pa}\right)$ for hydrogenotrophic methanogens; acetate $(30 \mathrm{mM})$ for acetoclastic methanogens; and a mixture of VFA $(10 \mathrm{mM}$ acetate, $10 \mathrm{mM}$ propionate and $5 \mathrm{mM}$ butyrate) for acetogenic bacteria. In this later case, the assessed effect is indirect as the specific activity of acetogens is only directly measured when hydrogenotrophic and acetoclastic activities are not rate limiting.

The assays were conducted in closed serum bottles of $25 \mathrm{~mL}$ of capacity, for liquid substrates (acetate, and VFA mixture), and of $70 \mathrm{~mL}$ for the gaseous substrate $\left(\mathrm{H}_{2} / \mathrm{CO}_{2}\right.$ $\left(80: 20 \% \mathrm{v} / \mathrm{v}\right.$, at $\left.1.7 \times 10^{5} \mathrm{~Pa}\right)$ and $\mathrm{N}_{2} / \mathrm{CO}_{2}(80: 20 \% \mathrm{v} / \mathrm{v}$, at $1.7 \times 10^{5} \mathrm{~Pa}$ ) used in the blank assay). The working volume was $12.5 \mathrm{~mL}$ in all assays and consisted in anaerobic medium containing deionized water with resazurin $(1 \mathrm{~g} / \mathrm{L})$ and sodium bicarbonate $(3 \mathrm{~g} / \mathrm{L})$. No reducing agent was added and the $\mathrm{pH}$ was corrected to values between 7.0 and 7.2. Anaerobic biomass was added at a final concentration of $3 \mathrm{~g} / \mathrm{L}$ of volatile solids (VS). The bottles were sealed with butyl rubber stoppers and aluminum caps, and the headspace was first flushed with $\mathrm{N}_{2} / \mathrm{CO}_{2}(80: 20 \% \mathrm{v} / \mathrm{v})$, and then depressurized to atmospheric pressure. Before adding the substrates and the pharmaceuticals, the bottles were incubated overnight $\left(37^{\circ} \mathrm{C}\right.$ and $\left.110 \mathrm{rpm}\right)$, to promote the consumption of the residual substrate by the biomass, and for temperature acclimation. After overnight incubation, the bottles headspace was flushed again with a mixture of $\mathrm{N}_{2} / \mathrm{CO}_{2}(80: 20 \% \mathrm{v} / \mathrm{v})$ to remove traces of methane, depressurized, and the substrates were added: $0.125 \mathrm{~mL}$ for liquid substrates (from 100x concentrated stock solutions) and $\mathrm{H}_{2} / \mathrm{CO}_{2}(80: 20 \% \mathrm{v} / \mathrm{v})$ (1 bar overpressure). Pharmaceutical compounds were added in concentrations ranging from $0.01 \mathrm{mg} / \mathrm{L}$ and $100 \mathrm{mg} / \mathrm{L}$ (Table 1). Initial methane production rate was assessed by measuring increasing pressure developed in the liquid substrate assays followed by analysis by Gas Chromatography (GC). The analyses were performed in a GC Chrompack 9000, equipped with a Propack Q, 80/100 mesh column, with $\mathrm{N}_{2} /$ Air and Argon as carrier gases, at a flow of 30 and $5 \mathrm{~mL} / \mathrm{min}$, respectively. Injector, column and detector temperatures were 110,35 and $220^{\circ} \mathrm{C}$, respectively. For $\mathrm{H}_{2} / \mathrm{CO}_{2}$ consumption, the decrease in pressure was assessed and the rate of methane production was obtained, by stoichiometric calculations (pressure decreases because 4 moles of $\mathrm{H}_{2} / \mathrm{CO}_{2}$ are needed to produce $1 \mathrm{~mol}$ of methane) (Supplementary Information Figure 1). Blank assays (B) were prepared without pharmaceuticals, and without substrate. Control assays (SC) were performed without pharmaceuticals but with the specific substrate, to determine the SMA without pharmaceuticals. All the assays were performed in triplicate.

IBP and EE2 stock solutions were prepared with organic solvents, and therefore additional controls were prepared (OSS - Control with organic solvent and specific substrate; OS - Control with organic solvent), in duplicate, in order to distinguish the effect of the pharmaceutical from the effect of the organic solvent (methanol and ethanol), as potential inhibitors or additional substrates (Table 1). In addition, due to the insolubility of IBP and EE2 at concentrations equal to or exceeding $100 \mathrm{mg} / \mathrm{L}$, assays with this concentration were performed by adding all the pharmaceutical compounds in powder directly in the incubation bottles. 
Table 2 Percentage of SMA inhibition in the presence of different substrates at increasing concentrations of CIP, DCF, IBP and EE2

\begin{tabular}{|c|c|c|c|c|c|c|c|c|}
\hline \multirow[t]{2}{*}{ Substrate } & \multirow[t]{2}{*}{ Pharmaceutical (mg/L) } & \multicolumn{7}{|c|}{ Inhibition (\%) } \\
\hline & & {$[0.01-0.1]$} & 1 & 5 & 10 & 50 & $100(\mathrm{~S})$ & $100(\mathrm{P})$ \\
\hline Acetate & CIP & 0 & $18 \pm 3$ & $16 \pm 7$ & $14 \pm 7$ & $45 \pm 8$ & $43 \pm 2$ & $76 \pm 4$ \\
\hline VFA & & 0 & $27 \pm 9$ & $25 \pm 5$ & $29 \pm 9$ & $28 \pm 5$ & $32 \pm 2$ & $21 \pm 6$ \\
\hline $\mathrm{H}_{2} / \mathrm{CO}_{2}$ & & 0 & 0 & 0 & 0 & 0 & 0 & 0 \\
\hline Acetate & $\mathrm{DCF}$ & 0 & 0 & 0 & 0 & $18 \pm 5$ & $39 \pm 4$ & $38 \pm 8$ \\
\hline VFA & & 0 & 0 & 0 & $16 \pm 5$ & $15 \pm 6$ & $28 \pm 7$ & 0 \\
\hline $\mathrm{H}_{2} / \mathrm{CO}_{2}$ & & 0 & 0 & 0 & 0 & 0 & 0 & 0 \\
\hline Acetate & IBP & 0 & 0 & 0 & 0 & $14 \pm 7$ & n.a & $20 \pm 6$ \\
\hline VFA & & 0 & 0 & 0 & 0 & 0 & n.a. & 0 \\
\hline $\mathrm{H}_{2} / \mathrm{CO}_{2}$ & & 0 & 0 & 0 & 0 & 0 & n.a. & 0 \\
\hline Acetate & EE2 & 0 & 0 & 0 & $6 \pm 3$ & $24 \pm 5$ & n.a. & $51 \pm 3$ \\
\hline VFA & & 0 & 0 & 0 & $17 \pm 4$ & $20 \pm 1$ & n.a. & $23 \pm 2$ \\
\hline $\mathrm{H}_{2} / \mathrm{CO}_{2}$ & & 0 & 0 & 0 & 0 & 0 & n.a. & 0 \\
\hline
\end{tabular}

\section{Statistical analysis}

Statistical analysis was performed using the GraphPad software, to verify if there were significant differences between the effects associated with the addition of pharmaceutical, as powder or as solution, at the maximum concentrations tested. F test was used to verify the homogeneity of variances, followed by the parametric unpaired $t$ test with a $p$-value of 0.05 , which was used to verify if the differences were significant.

\section{Results and discussion}

The anaerobic sludge used in this study showed methanogenic activity with all the substrates tested, as methane was produced in control assays (without pharmaceuticals). The highest SMA was obtained in $\mathrm{H}_{2} / \mathrm{CO}_{2}(515 \pm 52$ $\mathrm{mLCH}_{4} @ \mathrm{SPT} / \mathrm{gVS}$.day) assays, and in acetate and VFA, the SMA was $79 \pm 11 \mathrm{mLCH}_{4} @ \mathrm{SPT} / \mathrm{gVS}$.day and $82 \pm 13$ $\mathrm{mLCH}_{4} @ \mathrm{SPT} / \mathrm{gVS}$.day, respectively. In the assays performed with pharmaceuticals, no inhibition associated with the presence of pharmaceuticals was observed at the minimal concentration assessed $(0.01 \mathrm{mg} / \mathrm{L})$ (Table 2), which is the closest concentration to the ones found in real WWTP (Fonseca et al. 2013; Pereira et al. 2015; Sousa 2015). The SMA was also not affected by any of the tested pharmaceuticals at concentrations up to $0.1 \mathrm{mg} / \mathrm{L}$ (Table 2), which is higher than the concentrations found in WWTP (Fonseca et al. 2013; Pereira et al. 2015; Sousa 2015). It should be highlighted that hydrogenotrophic activity was not inhibited by any of the pharmaceuticals, regardless of concentration (Table 2). Overall, the anaerobic communities were most affected by the presence of
CIP, followed by EE2 and DCF, and less by IBP, when present at concentrations higher than $0.1 \mathrm{mg} / \mathrm{L}$. In the case of IBP or EE2, to assess the inhibitory effect, it was necessary to subtract the effect of the organic solvents and ethanol on the SMA, as they can serve as additional energy and carbon sources or function as microbial inhibitors (Supplementary Information Table 1). For instance, although the percentages of inhibition in the assays of EE2 with $\mathrm{H}_{2} / \mathrm{CO}_{2}$ were around $36 \%$, these were close to the inhibition obtained in the respective solvent control, OSS (around 38\%) (Table 2 and Supplementary Information Table 1), leading to the conclusion that EE2 did not affect the hydrogenotrophic activity. This conclusion is corroborated by the assay in which EE2 was added in powder at $100 \mathrm{mg} / \mathrm{L}$, where no inhibition was detected (Table 2).

The highest SMA inhibition percentages were obtained for the acetoclastic activity, showing that acetoclastic methanogens were the most affected (Table 2). However, for CIP, at concentrations up to $10 \mathrm{mg} / \mathrm{L}$ of CIP, acetogenic bacteria were the most sensitive to the presence of the antibiotic: $\approx 30 \%$ of inhibition. with $1-100 \mathrm{mg} / \mathrm{L}$ of CIP. On the other hand, at CIP concentrations higher than $10 \mathrm{mg} / \mathrm{L}$, acetoclastic activity was the most affected with circa $45 \%$ of inhibition (Table 2).

The same concentration of CIP added in solution or in powder resulted in different inhibitory percentages, with CIP in powder exerting the highest inhibition towards acetoclastic methanogens $(76 \pm 4 \%$ with CIP in powder, compared to $43 \pm 2 \%$ with CIP in solution) (Table 2, Supplementary Information Table 2 and Supplementary Information Figure 1). This difference may be related to the adsorption of CIP on the anaerobic sludge (Genç et al. 2013; Zhang et al. 2018). 


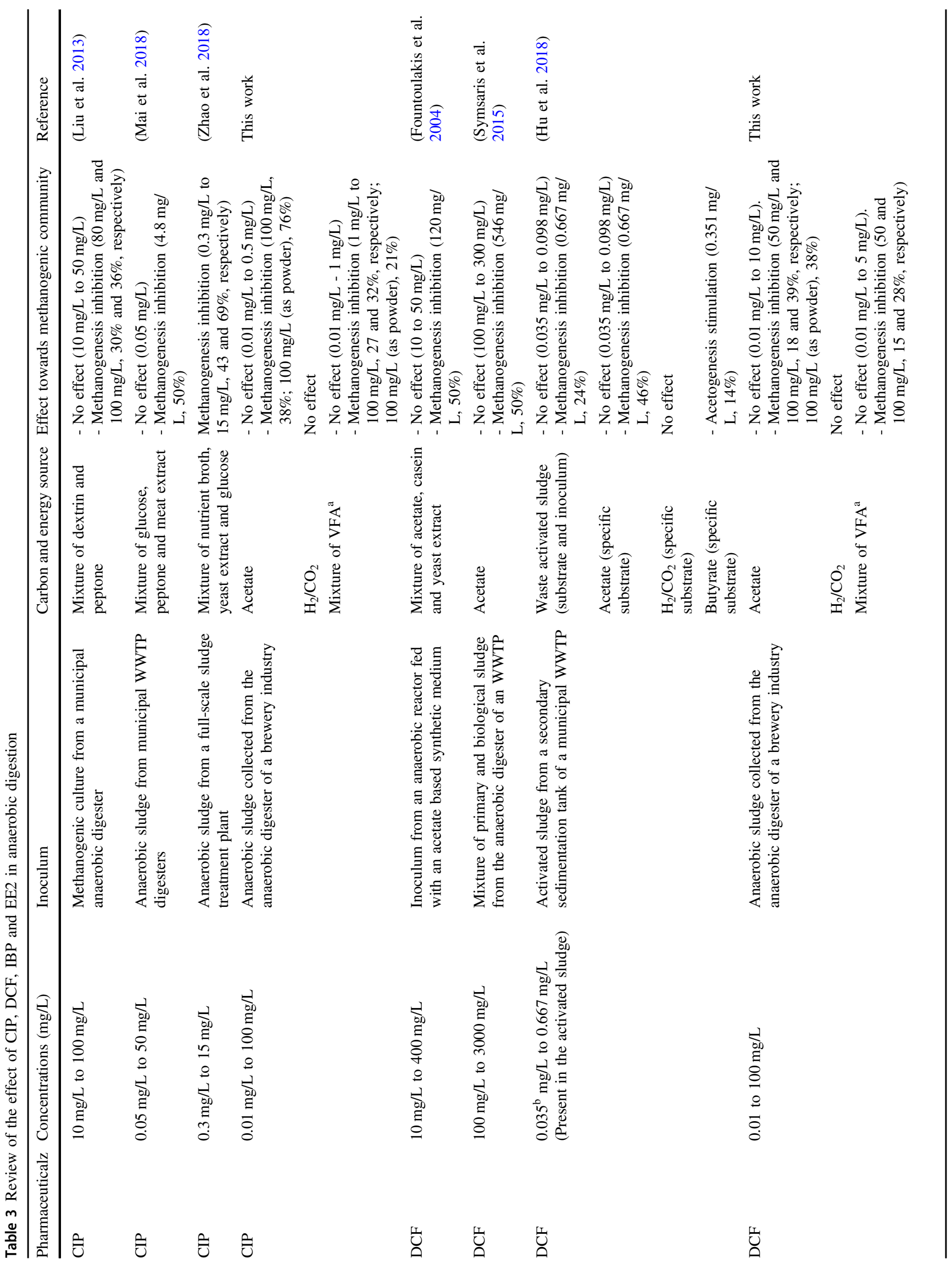




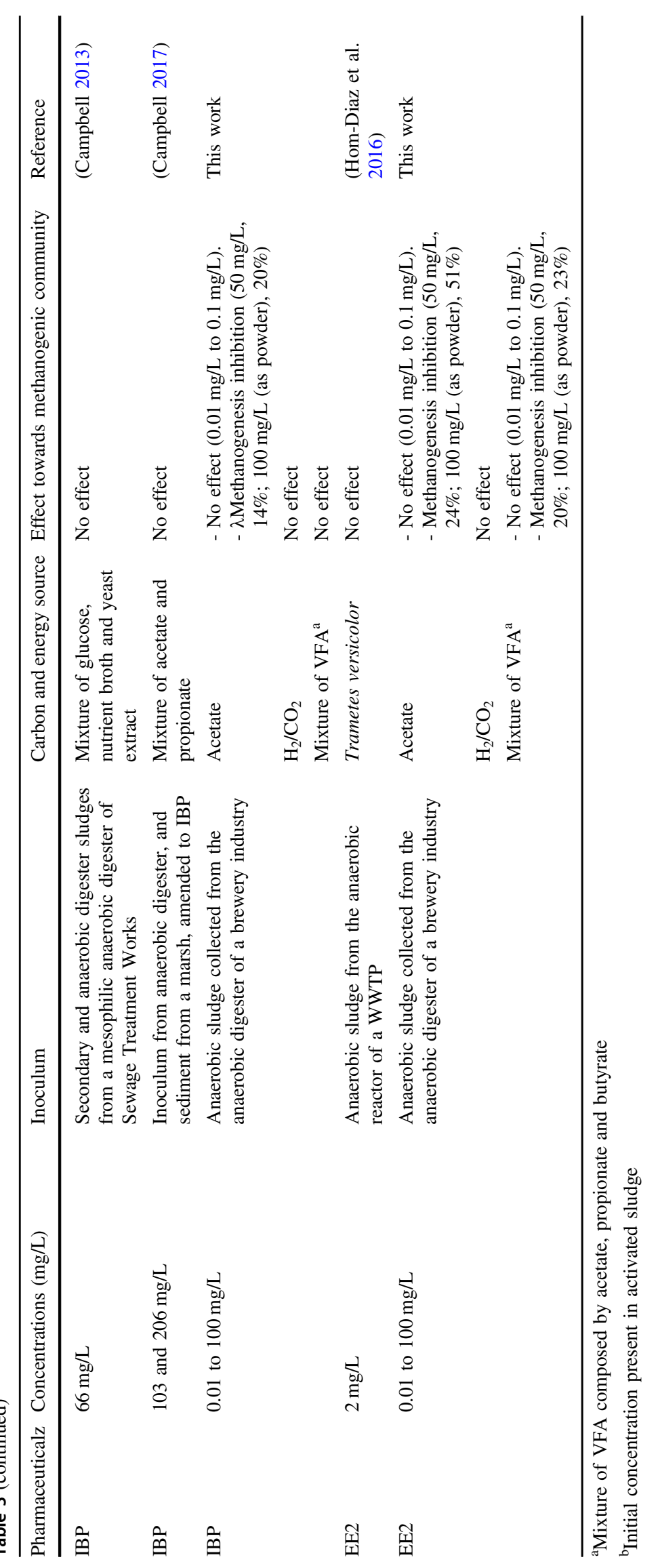


Given the lower solubility of CIP, it is possible that it was adsorbed onto the sludge when added as a powder to the medium at neutral $\mathrm{pH}$, increasing the contact between CIP and microbial cells and, consequently, the inhibitory effect. On the other hand, in the assay with VFA as substrate, the results obtained with CIP in solution $(32 \pm 2 \%)$ and in powder $(21 \pm 6 \%)$ were similar ( $p$ value of 0.0964$)$ ) (Table 2 and Supplementary Information Table 2). These results were close to the obtained by Liu et al. (2013), who reported a methanogenic inhibition of $36 \%$ with $100 \mathrm{mg} / \mathrm{L}$ of CIP. In that study the sludge was a methanogenic culture collected from a municipal anaerobic digester, which was fed with a mixture of dextrin and peptone (Table 3 ). Other studies showed higher sensitivity of anaerobic sludge to CIP for concentrations higher than $0.05 \mathrm{mg} / \mathrm{L}$ : $50 \%$ of inhibition at a concentration of CIP of $4.8 \mathrm{mg} / \mathrm{L}$, with a mixture of glucose, peptone and meat extract (Mai et al. 2018), and 43 and $69 \%$ at concentrations of $0.3 \mathrm{mg} / \mathrm{L}$ and $15 \mathrm{mg} / \mathrm{L}$ of CIP, respectively, with a mixture of nutrient broth, yeast extract and glucose (Zhao et al. 2018) (Table 3). The differences in the results presented in the literature may be justified by the use of different complex substrates, assessing the overall activity of the anaerobic community, instead of the activity of specific groups. In our study, only the acetoclastic and acetogenic communities were sensitive to CIP at concentrations higher or equal to $1.0 \mathrm{~g} / \mathrm{L}$, which is in good agreement with the study of Mai et al. (Mai et al. 2018), who observed a decrease in the relative abundance of these communities, in the presence of this antibiotic.

DCF only inhibited the acetogenic activity at concentrations $\geq 10 \mathrm{mg} / \mathrm{L}$, and the acetoclastic activity at concentrations $\geq 50 \mathrm{mg} / \mathrm{L}$, doubling the inhibition percentage when the DCF concentration increased from 50 to $100 \mathrm{mg} / \mathrm{L}$ (Table 2). When DCF was added as powder $(100 \mathrm{mg} / \mathrm{L})$, the inhibition of the acetoclastic activity was similar ( $p$ value of 0.8844 ) to the obtained with the solution of $100 \mathrm{mg} / \mathrm{L}$ of DCF (around 40\%) (Table 2 and Supplementary Information Table 2). However, no effect was observed towards the acetogenic plus methanogenic community when DCF was added as powder (Table 2), although $100 \mathrm{mg} / \mathrm{L}$ of DCF in solution caused an inhibition of $28 \pm 7 \%$. The differences between the inhibitory results obtained with DCF in powder and in solution may be related to the low DCF adsorption capability on the anaerobic sludge (Samaras et al. 2013). In solution, at $\mathrm{pH}$ 7, DCF is negatively charged due to its $\mathrm{pKa}=4.15$ (Zhang et al. 2008). As anaerobic sludge is also negatively charged (Jia et al. 1996; Alvarino et al. 2018), the adsorption between the DCF and the biomass will be reduced, due to growing repulsion electrostatic interactions and a reduction in $\pi-\pi$ interactions. Moreover, when DCF is added as powder, despite being solubilised in the medium, it will not be immediately available for the microorganisms as when added as solution, which may result in lower toxicity. These results are in good agreement with Fountoulakis et al. (Fountoulakis et al. 2004), who described $50 \%$ of inhibition of the acetoclastic methanogens with $120 \mathrm{mg} / \mathrm{L}$ of $\mathrm{DCF}$ and a mixture of acetate, casein and yeast extract (Table 3). However, inhibition of acetoclastic methanogenesis of $46 \%$ was obtained by $\mathrm{Hu}$ et al. (Hu et al. 2018), for $0.667 \mathrm{mg} / \mathrm{L}$ of DCF, with activated sludge from a secondary sedimentation tank of a municipal WWTP as inoculum, and acetate as substrate, revealing a higher susceptibility of that culture to DCF. A lower effect caused by DCF was obtained by Symsaris et al. (Symsaris et al. 2015), using acetate (Table 3).

The low sensitivity of hydrogenotrophic methanogens to DCF, compared to other microbial groups is also supported by other works (Table 3) (Symsaris et al. 2015; Hu et al. 2018).

Regarding IBP and EE2, the results obtained for the highest concentrations correspond to the effect of the pharmaceutical compound in solution discounting the effect of the correspondent inhibition caused by the OSS on the SMA (Supplementary Information Table 1). IBP did not cause inhibition to any group, except for the acetoclastic mehanogens (20\% with $100 \mathrm{mg} / \mathrm{L}$ ) (Table 2).

To date, the reports reveal no inhibitory effect of IBP at concentrations up to $206 \mathrm{mg} / \mathrm{L}$ (Campbell 2013, 2017) but the results were obtained with an anaerobic inoculum that was previously adapted to it (Campbell 2017), or using complex substrates (Campbell 2013), reflecting the overall activity of the anaerobic community, instead of the activity of specific groups involved in the methanogenic process (Table 3).

Concerning EE2, the inhibitory effect towards the acetoclastic methanogens was considered negligible for $10 \mathrm{mg} / \mathrm{L}$, while for $50 \mathrm{mg} / \mathrm{L}$, the acetoclastic activity was inhibited $24 \pm 5 \%$. Regarding the assay with VFA, inhibition of circa $20 \%$, was obtained for concentration equal and above $10 \mathrm{mg} / \mathrm{L}$ (Table 2). Any effect was observed on acetogenic activity, for concentrations up to $5 \mathrm{mg} / \mathrm{L}$, neither for acetoclastic at concentration up to $10 \mathrm{mg} / \mathrm{L}$ (Table 3). EE2 did not cause inhibition of the hydrogenotrophic community at any of the concentrations tested. To date, the reports available reveal no inhibitory effect of EE2 at concentrations up to $2 \mathrm{mg} / \mathrm{L}$ (Hom-Diaz et al. 2016).

\section{Conclusion}

In this work, the effect of pharmaceuticals ciprofloxacin (CIP), ibuprofen (IBP), diclofenac (DCF) and $17 \alpha$-ethinylestradiol (EE2) on anaerobic communities was 
evaluated. None of these pharmaceuticals affected the specific methanogenic activity at concentrations up to $0.1 \mathrm{mg} / \mathrm{L}$, which are closer to the ones found in the influents of WWTP. For higher concentrations (1 to $100 \mathrm{mg} / \mathrm{L}$ ), acetoclastic methanogens were the most affected, and were inhibited in $\approx 20 \%$ by $1 \mathrm{mg} / \mathrm{L}$ of CIP, and in circa $50 \%$ with higher antibiotic concentrations. The activity of acetogens together with methanogens was affected by all pharmaceuticals, except by IBP, while hydrogenotrophic methanogens were not affected by any pharmaceutical. Taking all the results in consideration, it can be concluded that the anaerobic communities were not severely affected by these compounds and therefore, the application of the anaerobic digestion for the treatment of wastewater, and for the digestion of sewage sludge contaminated with pharmaceuticals seems feasible. As future work, the effect of pharmaceuticals by using a real contaminated wastewater and real contaminated activated sludge should be assessed to determine the efficiency of the anaerobic digestion treatment with such contaminants.

Acknowledgements This study was supported by the Portuguese Foundation for Science and Technology (FCT) under the scope of the strategic funding of UID/BIO/04469/2019 unit and BioTecNorte operation (NORTE-01-0145-FEDER-000004) funded by the European Regional Development Fund under the scope of Norte2020 - Programa Operacional Regional do Norte. Ana Rita Silva holds an FCT grant SFRH/BD/131905/2017.

Funding This study was supported by the Portuguese Foundation for Science and Technology (FCT) under the scope of the strategic funding of UID/BIO/04469/2019 unit and BioTecNorte operation (NORTE-01-0145-FEDER-000004) funded by the European Regional Development Fund under the scope of Norte2020 - Programa Operacional Regional do Norte. Ana Rita Silva holds a Grant from FCT, reference SFRH/BD/131905/2017.

\section{Compliance with ethical standards}

Conflict of interest The authors declare that they have no conflict of interest.

Ethical approval This article does not contain any studies with human participants or animals performed by any of the authors.

Publisher's note Springer Nature remains neutral with regard to jurisdictional claims in published maps and institutional affiliations.

\section{References}

Alvarino T, Suarez S, Lema J, Omil F (2018) Understanding the sorption and biotransformation of organic micropollutants in innovative biological wastewater treatment technologies. Sci Total Environ 615:297-306. https://doi.org/10.1016/j.scitotenv. 2017.09.278

Alves MM, Vieira JAM, Pereira RMÁ et al. (2001) Effects of lipids and oleic acid on biomass development in anaerobic fixed-bed reactors, Part II: oleic acid toxicity and biodegradability. Water Res 35:264-270

Bouki C, Venieri D, Diamadopoulos E (2013) Detection and fate of antibiotic resistant bacteria in wastewater treatment plants: a review. Ecotoxicol Environ Saf 91:1-9. https://doi.org/10.1016/j. ecoenv.2013.01.016

Campbell AJ (2013) The behaviour of pharmaceuticals in anaerobic digester sludge (PhD thesis). University of Portsmouth

Campbell JK (2017) Biotransformation of atenolol and ibuprofen under methanogenic conditions and their influence on gas production and the microbial community (MSc thesis). The State University of New Jersey, New Brunswick, New Jersey

Carpenter DO, Arcaro K, Spink DC (2002) Understanding the human health effects of chemical mixtures. Environ Health Perspect 110:25-42

Carter LJ, Garman CD, Ryan J et al. (2014) Fate and uptake of pharmaceuticals in soil-earthworm systems. Environ Sci Technol 48:5955-5963

Carvalho PN, Pirra A, Basto MCP, Almeida CMR (2013) Activated sludge systems removal efficiency of veterinary pharmaceuticals from slaughterhouse wastewater. Environ Sci Pollut Res 20:8790-8800. https://doi.org/10.1007/s11356-013-1867-7

Cetecioglu Z, Ince B, Azman S (2013) Determination of anaerobic and anoxic biodegradation capacity of sulfamethoxasole and the effects on mixed microbial culture. In: BiodegradationEngineering and Technology. pp 223-249

Chen S, Li N, Dong B et al. (2017) New insights into the enhanced performance of high solid anaerobic digestion with dewatered sludge by thermal hydrolysis: organic matter degradation and methanogenic pathways. J Hazard Mater 342:1-9. https://doi.org/ 10.1016/j.jhazmat.2017.08.012

Corcoran J, Winter MJ, Tyler CR (2010) Pharmaceuticals in the aquatic environment: A critical review of the evidence for health effects in fish. Crit Rev Toxicol 40:287-304. https://doi.org/10. 3109/10408440903373590

Eiroa M, Costa JC, Alves MM et al. (2012) Evaluation of the biomethane potential of solid fish waste. Waste Manag 32:1347-1352. https://doi.org/10.1016/j.wasman.2012.03.020

Fick J, Söderström H, Lindberg R et al. (2009) Contamination of surface, ground, and drinking water from pharmaceutical production. Environ Toxicol Chem 28:2522-2527. https://doi.org/ 10.1897/09-073.1

Fonseca A, Cardoso M, Esteves V (2013) Determination of estrogens in raw and treated wastewater by high- performance liquid chromatography-ultraviolet detection. Environ Anal Toxicol 4: https://doi.org/10.4172/2161-0525.1000203

Fountoulakis M, Drillia P, Stamatelatou K, Lyberatos G (2004) Toxic effect of pharmaceuticals on methanogenesis. Water Sci Technol 50:335-340

Fountoulakis MS, Stamatelatou K, Lyberatos G (2008) The effect of pharmaceuticals on the kinetics of methanogenesis and acetogenesis. Bioresour Technol 99:7083-7090. https://doi.org/10. 1016/j.biortech.2008.01.008

Genç N, Dogan EC, Yurtsever M (2013) Bentonite for ciprofloxacin removal from aqueous solution. Water Sci Technol 68:848-856. https://doi.org/10.2166/wst.2013.313

Gonzalez-Gil L, Papa M, Feretti D et al. (2016) Is anaerobic digestion effective for the removal of organic micropollutants and biological activities from sewage sludge? Water Res 102:211-220. https://doi.org/10.1016/j.watres.2016.06.025

Hasan Z, Khan NA, Jhung SH (2016) Adsorptive removal of diclofenac sodium from water with Zr-based metal-organic frameworks. Chem Eng J 284:1406-1413. https://doi.org/10.1016/j.cej. 2015.08.087

Hom-Diaz A, Baldi F, Blánquez P et al. (2016) Exhausted fungal biomass as a feedstock for increasing methane production during 
the anaerobic digestion of organic wastes. Waste BiomassValoriz 7:307-315. https://doi.org/10.1007/s12649-015-9450-8

Hu J, Zhao J, Wang D et al. (2018) Effect of diclofenac on the production of volatile fatty acids from anaerobic fermentation of waste activated sludge. Bioresour Technol 254:7-15. https://doi. org/10.1016/j.biortech.2018.01.059

Jelic A, Gros M, Ginebreda A et al. (2011) Occurrence, partition and removal of pharmaceuticals in sewage water and sludge during wastewater treatment. Water Res 45:1165-1176. https://doi.org/ 10.1016/j.watres.2010.11.010

Ji JY, Xing YJ, Ma ZT et al. (2013) Acute toxicity of pharmaceutical wastewaters containing antibiotics to anaerobic digestion treatment. Chemosphere 91:1094-1098. https://doi.org/10.1016/j. chemosphere.2013.01.009

Jia XS, Fang HHP, Furumai H (1996) Surface charge and extracellular polymer of sludge in the anaerobic degradation process. Water Sci Technol 34:309-316. https://doi.org/10.1016/0273-1223(96) 00660-9

Jones OAH, Voulvoulis N, Lester JN (2005) Human Pharmaceuticals in Wastewater Treatment Processes. Crit Rev Environ Sci Technol 401-427. https://doi.org/10.1080/10643380590956966

Jung C, Son A, Her N et al. (2015) Removal of endocrine disrupting compounds, pharmaceuticals, and personal care products in water using carbon nanotubes: a review. J Ind Eng Chem 27:1-11. https://doi.org/10.1016/j.jiec.2014.12.035

Khetan SK, Collins TJ (2007) Human pharmaceuticals in the aquatic environment: a challenge to green chemistry. Chem Rev 107:2319-2364

Krzeminski P, Concetta M, Karaolia P et al. (2019) Performance of secondary wastewater treatment methods for the removal of contaminants of emerging concern implicated in crop uptake and antibiotic resistance spread: a review. Sci Total Environ 648:1052-1081. https://doi.org/10.1016/j.scitotenv.2018.08.130

Larsson DGJ, De Pedro C, Paxeus N (2007) Effluent from drug manufactures contains extremely high levels of pharmaceuticals. J Hazard Mater 148:751-755. https://doi.org/10.1016/j.jhazmat. 2007.07.008

Li WC (2014) Occurrence, sources, and fate of pharmaceuticals in aquatic environment and soil. Environ Pollut 187:193-201. https://doi.org/10.1016/j.envpol.2014.01.015

Liebig M, Moltmann JF, Knacker T (2006) Evaluation of measured and predicted environmental concentrations of selected human pharmaceuticals and personal care products. Environ Sci Pollut Res 13:110-119. https://doi.org/10.1065/espr2005.08.276

Liu Z, Sun P, Pavlostathis SG et al. (2013) Inhibitory effects and biotransformation potential of ciprofloxacin under anoxic/anaerobic conditions. Bioresour Technol 150:28-35. https://doi.org/ 10.1016/j.biortech.2013.09.125

Mai DT, Stuckey DC, Oh S (2018) Effect of ciprofloxacin on methane production and anaerobic microbial community. Bioresour Technol 261:240-248. https://doi.org/10.1016/j.biortech.2018.04.009

Malmborg J, Magnér J (2015) Pharmaceutical residues in sewage sludge: Effect of sanitization and anaerobic digestion. J Environ Manag 153:1-10. https://doi.org/10.1016/j.jenvman.2015.01.041

Mayumi D, Mochimaru H, Tamaki H et al. (2016) Methane production from coal by a single methanogen. Science (80-) 354:222-225

Mei X, Sui Q, Lyu S et al. (2018) Pharmaceuticals and personal care products in the urban river across the megacity Shanghai: occurrence, source apportionment and a snapshot of influence of rainfall. J Hazard Mater 359:429-436. https://doi.org/10.1016/j. jhazmat.2018.07.081

Pereira AMPT, Silva LJG, Meisel LM et al. (2015) Environmental impact of pharmaceuticals from Portuguese wastewaters: Geographical and seasonal occurrence, removal and risk assessment. Environ Res 136:108-119. https://doi.org/10.1016/j.envres.2014. 09.041
Quintana B, Weiss S, Reemtsma T (2005) Pathways and metabolites of microbial degradation of selected acidic pharmaceutical and their occurrence in municipal wastewater treated by a membrane bioreactor. Water Res 39:2654-2664. https://doi.org/10.1016/j. watres.2005.04.068

Radjenovic J, Petrovic M, Barceló D (2007) Analysis of pharmaceuticals in wastewater and removal using a membrane bioreactor. Anal Bioanal Chem 1365-1377. https://doi.org/10.1007/s00216006-0883-6

Radjenović J, Petrović M, Barceló D (2009) Fate and distribution of pharmaceuticals in wastewater and sewage sludge of the conventional activated sludge (CAS) and advanced membrane bioreactor (MBR) treatment. Water Res 43:831-841. https://doi.org/ 10.1016/j.watres.2008.11.043

Samaras VG, Stasinakis AS, Mamais D et al. (2013) Fate of selected pharmaceuticals and synthetic endocrine disrupting compounds during wastewater treatment and sludge anaerobic digestion. J Hazard Mater 244-245:259-267. https://doi.org/10.1016/j.jha zmat.2012.11.039

Scheurell M, Franke S, Shah RM, Hühnerfuss H (2009) Occurrence of diclofenac and its metabolites in surface water and effluent samples from Karachi, Pakistan. Chemosphere 77:870-876. https://doi.org/10.1016/j.chemosphere.2009.07.066

Silva AR, Martins PM, Lanceros-Mendez S et al. (2016) Ciprofloxacin wastewater treated by UVA photocatalysis: contribution of irradiated $\mathrm{TiO} 2$ and $\mathrm{ZnO}$ nanoparticles on the final toxicity as assessed by Vibrio fischeri. RSC Adv 6:95494-95503. https://doi. org/10.1039/C6RA19202E

Sousa IES (2015) Métodos de eliminação de fármacos e seus metabolitos ao nível das Estações de Tratamento de Águas Residuais. Universidade Fernando Pessoa, Oporto, Portugal

Subedi B, Loganathan BG (2016) Environmental emission of pharmaceuticals from wastewater treatment plants in the U.S.A. In: Persistent Organic Chemicals in the Environment: Status and Trends in the Pacific Basin Countries II Temporal Trends. American Chemical Society and Oxford University Press, pp 181-202

Symsaris EC, Fotidis IA, Stasinakis AS, Angelidaki I (2015) Effects of triclosan, diclofenac, and nonylphenol on mesophilic and thermophilic methanogenic activity and on the methanogenic communities. J Hazard Mater 291:45-51. https://doi.org/10.1016/j.jha zmat.2015.03.002

Ternes TA, Herrmann N, Bonerz M et al. (2004) A rapid method to measure the solid-water distribution coefficient (Kd) for pharmaceuticals and musk fragrances in sewage sludge. Water Res 38:4075-4084. https://doi.org/10.1016/j.watres.2004.07.015

Trapido M, Epold I, Bolobajev J, Dulova N (2014) Emerging micropollutants in water/wastewater: growing demand on removal technologies. Environ Sci Pollut Res 12217-12222. https://doi. org/10.1007/s11356-014-3020-7

US EPA (2009) Targeted national sewage sludge survey sampling and analysis technical report. Washington DC

Vasquez MI, Lambrianides A, Schneider M et al. (2014) Environmental side effects of pharmaceutical cocktails: What we know and what we should know. J Hazard Mater 279:169-189. https:// doi.org/10.1016/j.jhazmat.2014.06.069

Wu C, Spongberg AL, Witter JD, Sridhar BBM (2012) Ecotoxicology and environmental safety transfer of wastewater associated pharmaceuticals and personal care products to crop plants from biosolids treated soil. Ecotoxicol Environ Saf 85:104-109. https://doi.org/10.1016/j.ecoenv.2012.08.007

Zhang H, Jia Y, Khanal SK et al. (2018) Understanding the role of extracellular polymeric substances (EPS) on ciprofloxacin (CIP) adsorption in aerobic sludge, anaerobic sludge and sulfatereducing bacteria (SRB) sludge systems. Environ Sci Technol 52:6476-6486. https://doi.org/10.1021/acs.est.8b00568 
Zhang Y, Geißen S-U, Gal C (2008) Carbamazepine and diclofenac: removal in wastewater treatment plants and occurrence in water bodies. Chemosphere 73:1151-1161. https://doi.org/10.1016/j. chemosphere.2008.07.086

Zhao L, Ji Y, Sun P et al. (2018) Effects of individual and complex ciprofloxacin, fullerene $\mathrm{C} 60$, and $\mathrm{ZnO}$ nanoparticles on sludge digestion: Methane production, metabolism, and microbial community. Bioresour Technol 267:46-53. https://doi.org/10. 1016/j.biortech.2018.07.024

Zhou JL, Zhang ZL, Banks E et al. (2009) Pharmaceutical residues in wastewater treatment works effluents and their impact on receiving river water. J Hazard Mater 166:655-661. https://doi. org/10.1016/j.jhazmat.2008.11.070 